\title{
三次元異材接合体の角部における熱残留応力の特異場の特性*
}

\author{
古口日出男*1, 谷口昂*2

\section{Characteristics of Stress Singularity Field of Residual Thermal Stresses at Vertex in Three-Dimensional Bonded Joints} \\ Hideo KOGUCHI ${ }^{* 3}$ and Takashi TANIGUCHI \\ ${ }^{* 3}$ Department of Mechanical Engineering, Nagaoka University of Technology, \\ 1603-1 Kamitomioka-cho, Nagaoka-shi, Niigata, 940-2188 Japan

\begin{abstract}
A mismatch of material properties may cause stress singularity, which lead to failures of bonding part in joints. The stress singularity of thermal residual stresses occurs in a cooling process after bonding the joints at a high temperature. In the present paper, boundary element method and an eigen value analysis based on finite element method are used for evaluating the intensity of singularity for residual thermal stresses at a vertex in three-dimensional joints. Three-dimensional boundary element program based on the fundamental solution for two-phase isotropic body is used for calculating the stress distribution in a three-dimensional joint. Angular function in the singular stress field at the vertex in the three-dimensional joint is calculated using eigen vector determined from the eigen analysis. The distribution of angular function of stress components is well agreed with and the distribution of residual thermal stresses. Furthermore, the angular function for $\sigma_{\theta \theta}$ has a singularity at the cross points of the interface and side free surfaces. In the present paper, the intensity of singularity at the vertex in three-dimensional joints is determined using the characteristic of angular function and the coefficient of power law singularity of stress distribution against the distance from the origin of singularity.
\end{abstract}

Key Words : Stress Singularity, Interface, Elasticity, Adhesive Joints, Boundary Element Method, Thermal Stresses

\section{1. 緒言}

当研究者らは，これまで二次元・三次元異材接合体 の界面端部に発生する応力特異場の特性について調べ てきた(1) (11). 特異応力場は応力特異点を原点とする 極座標系において, 特異点からの距離の関数として表 されることはよく知られている(12). 二次元接合体の 接合端における特異応力場の一般解は二次元弾性論に より導かれており，それを用いれば応力特異点近傍の 応力分布を求めることができる(6)(9)(10)(13). 三次元接合 体の場合には, 理論解析上の困難さのため数值解析に より応力分布を求めざるを得ない状況にある.

ところで, 三次元接合体の特異応力場は特異点から の距離に対する分布に比べ，接合界面端の角部を原点 とした球座標系の角度方向の分布については，まだ不 明の点がある. 例えば, 図 1 に示すように応力特異線 も角部の $\theta, \phi(r=$ 一定)に対する応力分布に影響を 与えていると考えられるが, よくわかっていない.こ れが三次元特異応力場の特徵を決めているともいえ

* 原稿受付 2008 年 1 月 22 日.

*1 正員, フェロー, 長岡技術科学大学工学部 (雪 940-2188 長岡 市上富岡町 1603-1)

*2 准員, 長岡技術科学大学工学部.

E-mail : koguchi@mech.nagaokaut.ac.jp
る.一般に, 特異応力場は

$$
\sigma_{i j}(r, \theta, \phi)=\sum_{m} \bar{K}_{m} r^{-\lambda m} f_{i j}^{m}(\theta, \phi)
$$

のように表される.ここで, $r$ は応力特異点からの距 離, $\bar{K}_{m}$ は特異応力場の強さ, $f_{i j}^{m}(\theta, \phi)$ は応力場の角 度依存性を表す関数, $\lambda_{m}$ は特異性のオーダである.

本研究では電子デバイスに見られる材料の組合せに 対して, 三次元角部の熱残留応力の特異応力場の分布 と強さについて調べる. 特に有限要素法による固有值 解析により応力特異性のオーダを求め, その特異性の

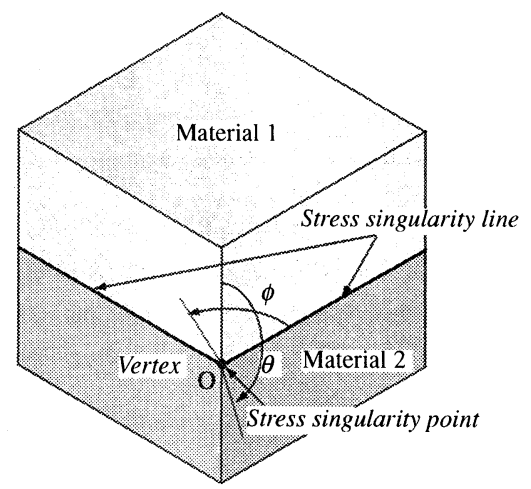

Fig. 1 Three-dimensional bonded structures 
オーダに対応する固有べクトルから得られる応力場の 角度依存関数 $f_{i j}(\theta, \phi)$ と三次元境界要素法から得ら れる熱残留応力分布を比較する。 また，本論文では二 次元接合体の応力分布の理論式により三次元応力特異 場における角度依存関数の近似式の導出を試みる。特 に, 界面はく離に関係する応力成分について詳細に調 べる. 最後に, 三次元接合体角部の応力特異性の強さ を応力特異線の影響も考慮して求める方法を示す.

\section{2. 解 析 方 法}

三次元接合体の応力は境界要素法により求める。そ の式を以下に示す。

$$
\begin{gathered}
c_{i j}(P) u_{j}(P)=\int_{\Omega} U_{i j}^{*}(P, Q) t_{j} \mathrm{~d} S(Q) \\
\quad-\int_{\Omega} T_{i j}^{*}(P, Q) u_{j} \mathrm{~d} S(Q) \ldots \ldots \ldots \ldots \ldots
\end{gathered}
$$

ここで, $c_{i j}$ は領域の形状により決まる定数, $\Omega$ は解 析領域の境界, $U_{i j}^{*}$ と $T_{i j}^{*}$ は変位と作用力に対する基 本解であるＰおよび $Q$ はそれぞれ境界上の観測点 とソース点である. $t_{j}$ と $u_{j}$ は作用力ベクトルと変位 ベクトルである.また, 本研究では Rongvedの二相 体の解を基本解として用いているため, 界面における 要素分割を必要としない.

ここでは, 応力特異性のオーダを有限要素法の定式 化に基づく固有值解析により求める. 固有値 $p$ は特 異性のオーダ $\lambda$ と $\lambda=1-p$ 関係がある.この值 $p$

Table 1 Material properties and thermal stress

\begin{tabular}{|c|c|c|c|c|}
\hline & $\begin{array}{c}\text { Young's } \\
\text { modulus }\end{array}$ & $\begin{array}{c}\text { Thermal } \\
\text { expansion }\end{array}$ & $\begin{array}{c}\text { Poisson's } \\
\text { ratio }\end{array}$ & $\begin{array}{c}\text { Thermal } \\
\text { stress }\end{array}$ \\
\cline { 2 - 5 } & $E[\mathrm{Gpa}]$ & $\alpha[\mathrm{ppm} / \mathrm{K}]$ & $v$ & $\sigma_{t h}[\mathrm{Mpa}]$ \\
\hline Silicon & 166 & 0.30 & 0.26 & 161 \\
\hline Resin & 2.74 & 33 & 0.38 & 58.4 \\
\hline
\end{tabular}

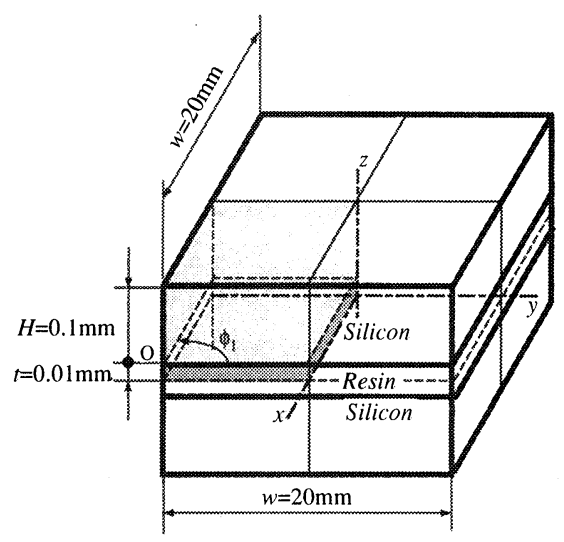

Fig. 2 A model of bonded structures for analysis
は次式の固有方程式を解くことにより求められ $る^{(14)}$.

$$
\left(p^{2}[A]+p[B]+[C]\right)\{u\}=0
$$

ここで, $[A],[B]$ および $[C]$ は弾性定数からなる行 列, $\{u\}$ は変位ベクトルである.

本論文では, 境界要素法により熱残留応力の特異応 力場の応力分布を求める. 表面だけ要素分割すればよ い境界要素法を用いることにより, 有限要素法で同様 の計算をする場合に比べ，少ないデータで計算でき る.また，基本解に二相体の解を用いることにより， 界面上および界面端の熱応力の特異応力場の分布を高 精度に求めることができるなどの利点がある．等方・ 均質な弾性体において, $\Delta T$ の温度変化を受けるとき の自由熱膨張に伴う熱ひずみ $\varepsilon_{i j}^{T}$ は次式で与えられ る.

$$
\varepsilon_{i j}^{T}=\alpha \Delta T \delta_{i j}
$$

ここで, $\alpha$ は材料の線膨張係数であり, $\delta_{i j}$ は Kroneckerのデルタである. 自由熱膨張が拘束されている と熱応力が発生する. 材料は Hooke 則に従うものと すると, 応力 $\sigma_{i j}$ とひずみ $\varepsilon_{i j}$ の関係は次式のように 表される.

$$
\varepsilon_{i j}=\frac{1+\nu}{E}\left(\sigma_{i j}-\frac{\nu}{1+\nu} \sigma_{k k} \delta_{i j}\right)+\alpha \Delta T \delta_{i j}
$$

ここで, $E$ はヤング率, レはポアソン比である.

式(4) から応力をひずみで表すと式(5)が得られ る.

$$
\sigma_{i j}=\frac{E}{1+\nu}\left(\varepsilon_{i j}+\frac{\nu}{1-2 \nu} \varepsilon_{k k} \delta_{i j}\right)-\frac{E}{1-2 \nu} \alpha \Delta T \delta_{i j}
$$

なお，ひずみは式 (1)をソース点の座標で微分した式 から求める. 二つの材料がある温度 $T$ で完全に接合 された後, 温度変化 $\Delta T$ を受ける場合, Duhamel の 定理に基づけば，側面に仮想表面力が作用する通常の 弾性問題と等価な問題として取扱うことができる.

\section{3. 解析モデルおよび解析条件}

本研究の解析モデルおよび寸法を図 2 に示す．被着 材(Silicon)の寸法は高さ $H$ が $0.1 \mathrm{~mm}$, 幅 $w$ が 20 $\mathrm{mm}$ である. 中間層(Resin)の厚さ $t$ は $0.01 \mathrm{~mm}$ と し, SiliconをResinで接合する構造をしている。各 材料の物性値については，表 1 に示すとおりである. 図 2 に示す解析モデルの側面にそれぞれの材料特性に 応じた熱応力 $E_{i} \alpha_{i} \Delta T /\left(1-2 \nu_{i}\right)(i=1,2)$ を加え応力解 析を行った.そして, 解析後に加えた熱応力を除去す ることにより, 熱残留応力を求めた. 表 1 にモデルの 
側面に加えた熱応力を示す，本論文では，被着材(Silicon）は同じ材料としているため，応力と変位は中間 層の中央面に関して対称である。ここでは, 要素数を 少なくするためにモデルの対称性を考慮して要素分割 を行った。

\section{4. 解析結果および考察}

$4 \cdot 1$ 固有值解析 固有值解析には既報(15) で説明 した有限要素法モデルを用いた．解析モデルの要素分 割図を図 3 に示す。図 $3(\mathrm{a})$ は特異点を原点とする単 位球表面を $\phi$ 方向と $\theta$ 方向に分割したもので，(b) は $\phi-\theta$ 面に展開したものである.いま， $\phi_{1}$ を図 2 に 示すように解析する応力特異点で交わる応力特異線の なす角度とする.ここでは，三次元接合体角部の特異 性および応力特異線上の特異性を調べるために $\phi_{1}=$ $90^{\circ}$ および $\phi_{1}=180^{\circ}$ の場合について解析を行う。要 素サイズは $(\theta \times \phi)=6^{\circ} \times 6^{\circ}$ である. 表 2 に特異性の オーダ $\lambda$ の解析結果を示す。本論文中では角部から の特異性を $\lambda_{\text {vertex }}$, 応力特異線上の特異性を $\lambda_{\text {side }}$ とす る。なお, $\phi_{1}=90^{\circ}$ について $p=1$ の三重根, $\phi_{1}=180^{\circ}$ について $p=1$ の五重根が得られた。 $p=1$ の重根があ る場合, 三重根の場合には $\ln \bar{r},(\ln \bar{r})^{2}$, 五重根の場 合には $\ln \bar{r},(\ln \bar{r})^{2},(\ln \bar{r})^{3},(\ln \bar{r})^{4}$ の対数特異性が 発生するため, 接合端部の応力場は次のように表すこ

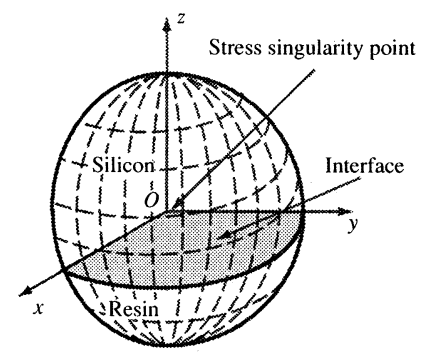

(a) A mesh division of the surface of a unit sphere with the origin at the vertex

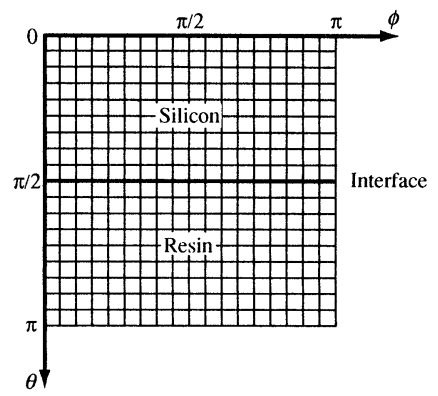

(b) A mesh on the developed $\theta \times \phi$ plane

Fig. 3 FEM model for eigen analysis
とができる(12).

$$
\begin{array}{r}
\sigma_{i j}(\bar{r}, \theta, \phi)=K_{1 i j} f_{1 i j}(\theta, \phi) \bar{r}^{-\lambda}+K_{2 i j} f_{2 i j}(\theta, \phi) \\
\quad+\sum_{k=3}^{M} K_{k i j} f_{k i j}(\theta, \phi)(\ln \bar{r})^{k-2} \cdots \cdots \cdots \cdots \cdots \cdots(6) \cdots \cdots \cdots(6)
\end{array}
$$

ここで， $\bar{r}=r / t, M=4$ (三重根の場合)，6(五重根の 場合)である。

$4 \cdot 2$ 固有ベクトル解析 角部 [図 3(b)の要素 分割 $\left.\phi_{1}=90^{\circ}\right]$ における固有值 $p$ に対応する固有変位 ベクトル $[$ 式 $(2)$ の $\{u\}]$ から得られる角度依存関数 $f_{i j}(\theta, \phi)$ の分布 $\left(5^{\circ} \leqq \theta \leqq 175^{\circ}, 5^{\circ} \leqq \phi \leqq 85^{\circ}\right)$ を図 4 に 示す。これらの分布はすべて $\theta=90^{\circ}, \phi=45^{\circ}$ におけ る $f_{\theta \theta}$ の值で正規化して得られたものである。これは 通常, $f_{i j}(\theta, \phi)$ の最大值が 1 になるように正規化する ことが望ましいことであるが, $f_{\theta \theta}$ が $\theta=90^{\circ}$ で, 特異 応力線に近づくに伴い $\left(\phi \rightarrow 0\right.$ および $\left.90^{\circ}\right)$ 発散するた めである.さらに， $f_{i j}$ の成分には $\phi=45^{\circ}$ で零となる ものがあるため, ここではすべての $f_{i j}$ に対して，同 じ值で正規化を行っている。

次に，はく離に関係していると考えられる $\sigma_{\theta \theta}$ の角 度依存関数 $f_{\theta \theta}$ について調べる. 図 5 は特異性の才ー ダに関する固有方程式を導出する際に用いる球座標系 である.ここで, $r$ は原点 $\mathrm{O}$ から内点 $\mathrm{P}$ までの距離, $r_{0}$ は球の半径である. 固有方程式の定式化の際, 無次 元距離 $\rho=r / r_{0}$ で特異場内の変位場を定義する.この 球面上の応力分布が, $f_{i j}$ として求められる.ところ で， $\theta$ を一定としたときの $\phi$ に対する応力は図 6 のよ うに自由表面と界面との交線である応力特異線からの 影響を受けると考えられる. Monchai ら ${ }^{(16)}$ は応力特 異線に沿って三次元応力場を調べ, 応力特異線近傍の 特異応力場は指数特異性と対数特異性を組合わせた式 で表すことができることを示した，本研究の解析モデ ルの角部近傍には 2 本の応力特異線があり, それぞれ の応力特異線からの距離に応じて内部の応力分布に影 響を与えていると考えられる。これらのことから，角 部近傍の応力分布の角度依存関数は図 5 の球内におい て式( 7 )のように書くことができると考える.ここ

Table 2 List of eigen values and the order of stress singularity for joints of $\phi=90^{\circ}$ and $180^{\circ}$

\begin{tabular}{|c|c|c|c|c|}
\hline \multirow{2}{*}{} & \multicolumn{2}{|c|}{$\begin{array}{c}\text { Stress singularity } \\
\text { of the vertex } \\
\phi=90^{\circ}\end{array}$} & \multicolumn{2}{c|}{$\begin{array}{c}\text { Stress singularity } \\
\text { of the side } \\
\phi=180^{\circ}\end{array}$} \\
\cline { 2 - 5 } & $p_{\text {vertex }}$ & $\lambda_{\text {vertex }}$ & $p_{\text {side }}$ & $\lambda_{\text {side }}$ \\
\hline 1 & 1.000 & 0.000 & 1.000 & 0.000 \\
\hline 2 & 1.000 & 0.000 & 1.000 & 0.000 \\
\hline 3 & 1.000 & 0.000 & 1.000 & 0.000 \\
\hline 4 & 0.605 & 0.395 & 1.000 & 0.000 \\
\hline 5 & - & - & 1.000 & 0.000 \\
\hline 6 & - & - & 0.682 & 0.318 \\
\hline
\end{tabular}




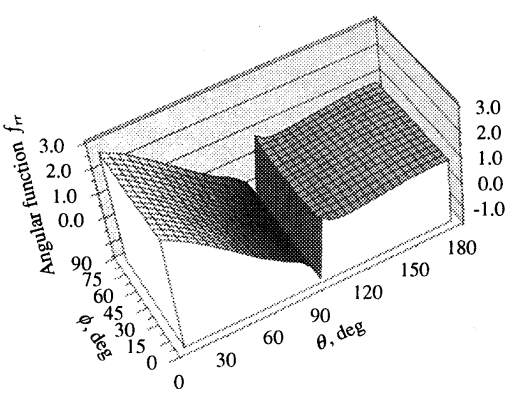

(a) Distribution of angular function $f_{r r}$

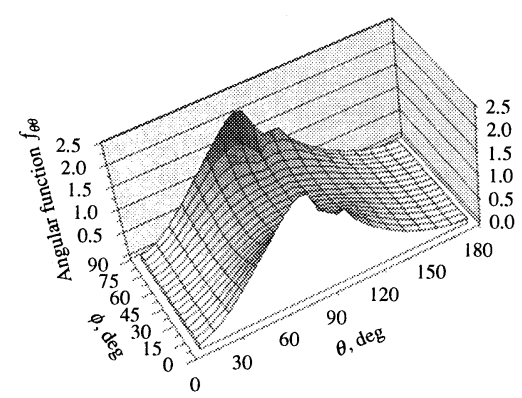

(b) Distribution of angular function $f_{\theta \theta}$

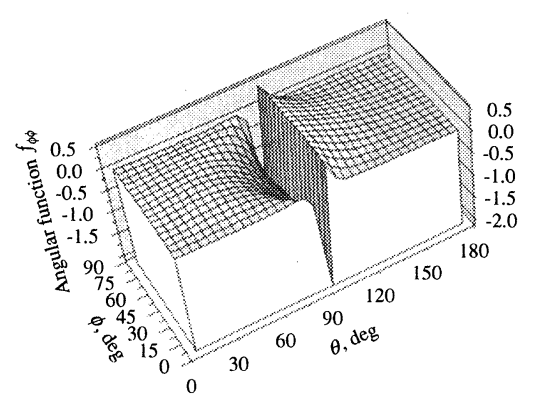

(c) Distribution of angular function $f_{\phi \phi}$

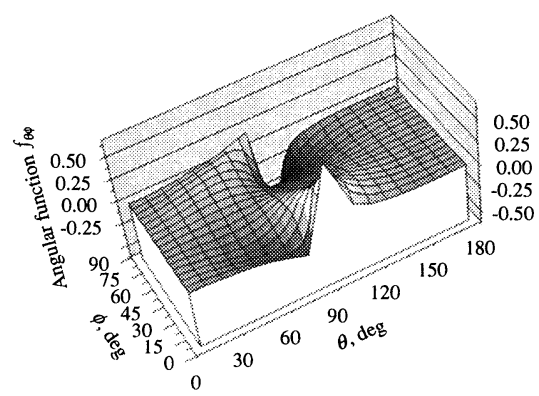

(d) Distribution of angular function $f_{\theta \phi}$

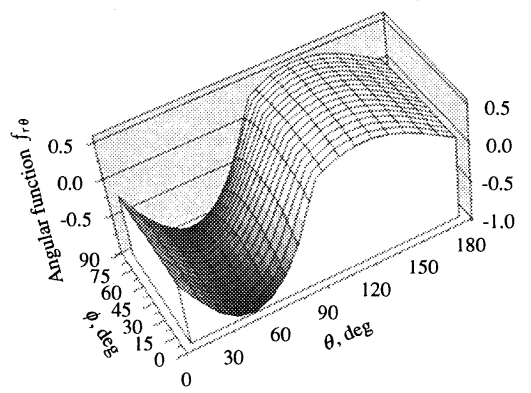

(e) Distribution of angular function $f_{r \theta}$

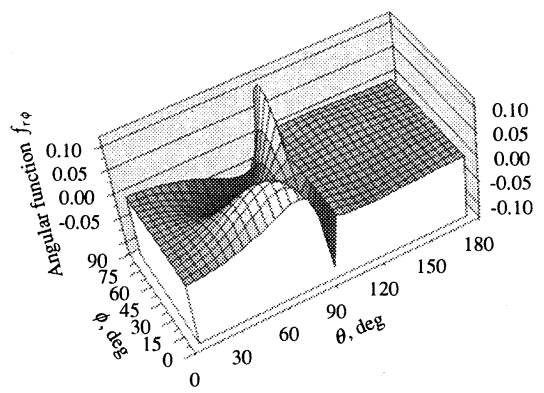

(f) Distribution of angular function $f_{r \phi}$

Fig. 4 Distribution of angular function $f_{i j}$ on the $\theta-\phi$ plane

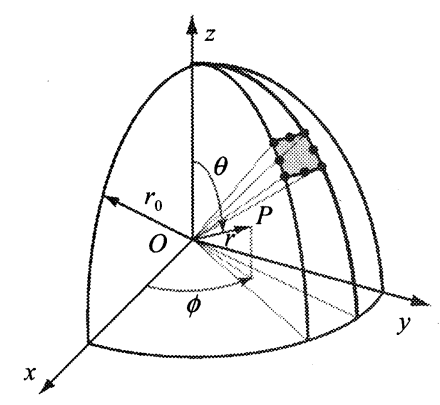

Fig. 5 Spherical coordinate system with an origin at the singularity point

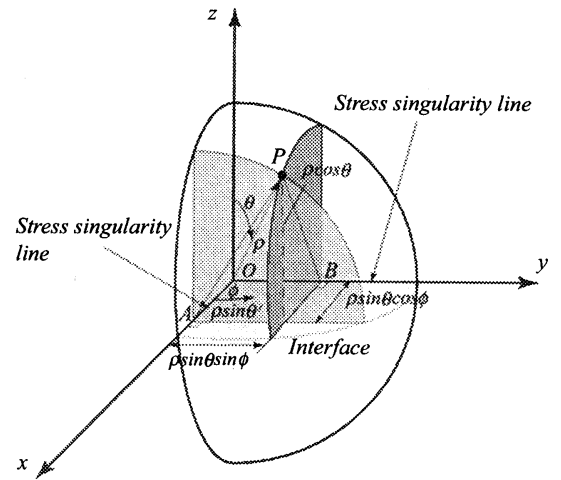

Fig. 6 The influence of sigularity line on stress singularity field 
で, $L_{1 \theta \theta} \sim L_{6 \theta \theta}$ は応力特異線上の点の特異応力場の強 さであり, 添字の $A, B$ は図 6 に扔ける各応力特異線 上の点, $\lambda_{\text {side }}$ は応力特異線近傍の応力場の特異性の才 ーダである。

$$
\begin{aligned}
& f_{\theta \theta}^{\phi}\left(\rho_{A}, \rho_{B}, \phi, \lambda_{\text {side }}\right)=L_{1 \theta \theta}^{A} \rho_{A}^{-\lambda_{\text {side }}}+L_{1 \theta \theta}^{B} \rho_{B}^{-\lambda_{\text {side }}}+L_{2 \theta \theta} \\
& \quad+\sum_{k=3}^{6} L_{k \theta \theta}^{A}\left(\ln \rho_{A}\right)^{k-2}+\sum_{k=3}^{6} L_{k \theta \theta}^{B}\left(\ln \rho_{B}\right)^{k-2}
\end{aligned}
$$

ここで, $\rho_{A}, \rho_{B}$ は球座標系の点 $\mathrm{P}(\rho, \theta, \phi)$ から各応力 特異線までの距離で, それぞれ $\rho_{A}=\rho \sqrt{1-\sin ^{2} \theta \cos ^{2} \phi}$, $\rho_{B}=\rho \sqrt{1-\sin ^{2} \theta \sin ^{2} \phi}$ である.さらに, ここでは $\rho$ $=1$ とする.

図 7 は, $\theta=90^{\circ}$ (界面)に扔ける $f_{\theta \theta}$ を角度 $\phi$ に対し て○で示したものである。これを実線のように式（7） で近似し， $\phi$ 方向の特異応力場の強さ $L_{\theta \theta}$ を得た。得 られた係数を表 3 に示す。本論文のモデルでは, 界面

Table 3 Coefficients of $f_{\theta \theta}$ determined by approximating for $\phi$

\begin{tabular}{|c|c|}
\hline$L_{1 \theta \theta}$ & $L_{2 \theta \theta}$ \\
\hline 0.532 & -0.179 \\
\hline
\end{tabular}

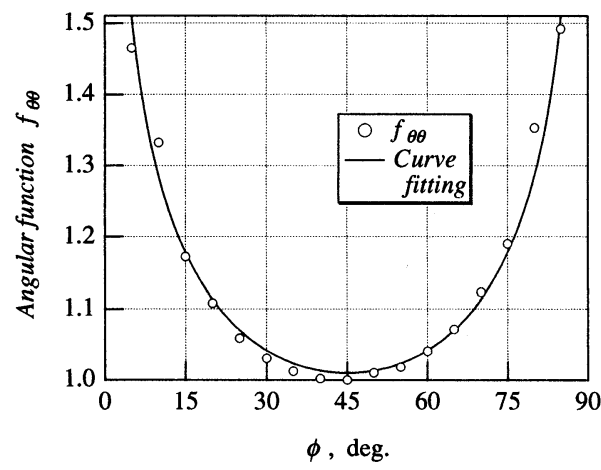

Fig. 7 Profile of $f_{\theta \theta}$ at $\theta=90^{\circ}$ for $\phi$

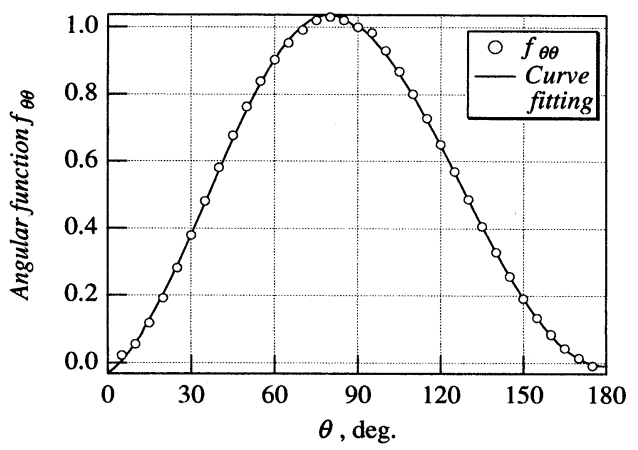

Fig. 8 Profile of $f_{\theta \theta}$ at $\phi=45^{\circ}$ for $\theta$
と側面とのなす角が両側面で同じであるので $L_{k \theta \theta}^{A}, L$ ${ }_{k \theta \theta}^{B}(k=1 \sim 6)$ は同じである. 図 8 は, $\phi=45^{\circ}$ における $f_{\theta \theta}$ を $\theta$ に対して○で示したものである.なお，実線 は後述する近似曲線である. $\phi=45^{\circ}$ における応力分 布は接合体角部を構成する側面からの影響が少ないと 考え, 二次元接合体の理論解を用いて図 8 の応力分布 を近似することを試みる．Bogy ${ }^{(6)}$, 井上，古口ら ${ }^{(13)}$ により求められた二次元接合体の $\theta$ 方向の応力分布 は, 式 (8)のAiry の応力関数 $\Phi$ を Mellin 変換を用 いて得られ，式( 9$) 〜(11)$ のうに表される.

$$
\begin{aligned}
& \nabla^{4} \Phi=0 \\
& f_{\theta \theta}^{\theta}\left(\lambda_{\text {vertex }}, \theta\right)=\lambda_{\text {vertex }}\left(\lambda_{\text {vertex }}-2\right) \\
& \quad \times\left\{a \sin \left[\left(\lambda_{\text {vertex }}-2\right) \theta\right]+b \cos \left[\left(\lambda_{\text {vertex }}-2\right) \theta\right]\right. \\
& \left.\quad+c \sin \left[\lambda_{\text {vertex }} \theta\right]+d \cos \left[\lambda_{\text {vertex }} \theta\right]\right\} \cdots \cdots(9) \\
& f_{r r}^{\theta}\left(\lambda_{\text {vertex }}, \theta\right)=-\left(\lambda_{\text {vertex }}-1\right) \\
& \quad \times\left\{a\left(\lambda_{\text {vertex }}-2\right) \sin \left[\left(\lambda_{\text {vertex }}-2\right) \theta\right]\right. \\
& \quad+b\left(\lambda_{\text {vertex }}-2\right) \cos \left[\left(\lambda_{\text {vertex }}-2\right) \theta\right]
\end{aligned}
$$

Table 4 Coefficients in Eqs. (9)

\begin{tabular}{|c|c|c|c|c|}
\hline & $a$ & $b$ & $c$ & $d$ \\
\hline $0^{\circ} \leq \boldsymbol{\theta} \leq 90^{\circ}$ & -0.620 & -0.818 & -1.10 & 0.762 \\
\hline $90^{\circ}<\theta \leq 180^{\circ}$ & -0.635 & -0.324 & 0.743 & -0.0474 \\
\hline
\end{tabular}

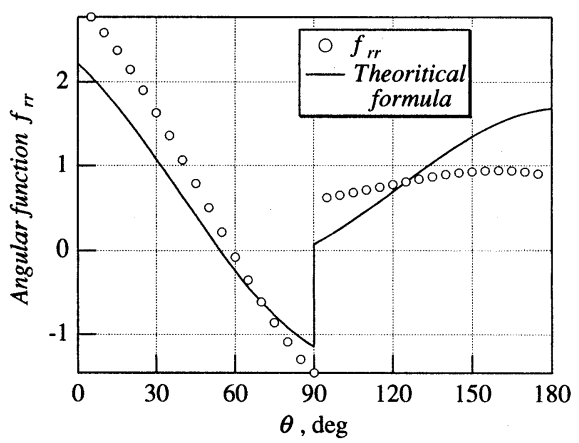

Fig. 9 Profile of $f_{r r}$ at $\phi=45^{\circ}$ for $\theta$

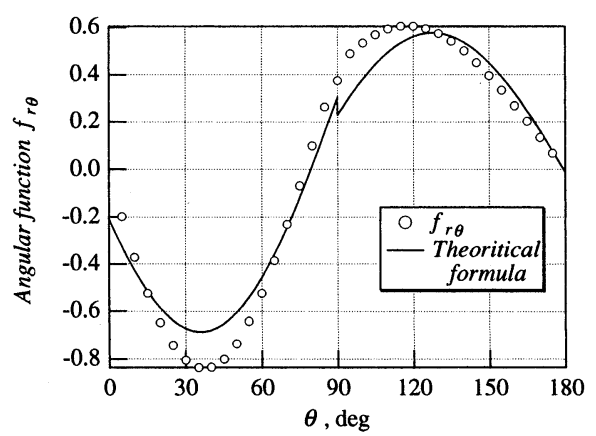

Fig. 10 Profile of $f_{r \theta}$ at $\phi=45^{\circ}$ for $\theta$ 


$$
\begin{aligned}
& +c\left(\lambda_{\text {vertex }}+2\right) \sin \left(\lambda_{\text {vertex }} \theta\right) \\
& \left.+d\left(\lambda_{\text {vertex }}+2\right) \cos \left(\lambda_{\text {vertex }} \theta\right)\right\} \\
& f_{r \theta}^{\theta}\left(\lambda_{\text {vertex }}, \theta\right)=\left(\lambda_{\text {vertex }}-1\right) \\
& \times\left\{a\left(\lambda_{\text {vertex }}-2\right) \cos \left[\left(\lambda_{\text {vertex }}-2\right) \theta\right]\right. \\
& -b\left(\lambda_{\text {vertex }}-2\right) \sin \left[\left(\lambda_{\text {vertex }}-2\right) \theta\right] \\
& +c \cdot \lambda_{\text {vertex }} \cos \left(\lambda_{\text {vertex }} \theta\right) \\
& \left.-d \cdot \lambda_{\text {vertex }} \sin \left(\lambda_{\text {vertex }} \theta\right)\right\} \cdot
\end{aligned}
$$

ここで, $a \sim d$ は末定係数である.ただし, 特異性の オーダ $\lambda$ は二次元接合体の值ではなく, 三次元角部で の $\lambda_{\text {vertex }}$ を用い, $0^{\circ} \leqq \theta \leqq 90^{\circ}$ お び $90^{\circ}<\theta \leqq 180^{\circ}$ に ついて，それぞれ $f_{\theta \theta}$ を近似し，末定係数 $a \sim d$ を求 めた，得られた係数を表 4 に示す。この係数を $f_{\theta \theta}$ 以

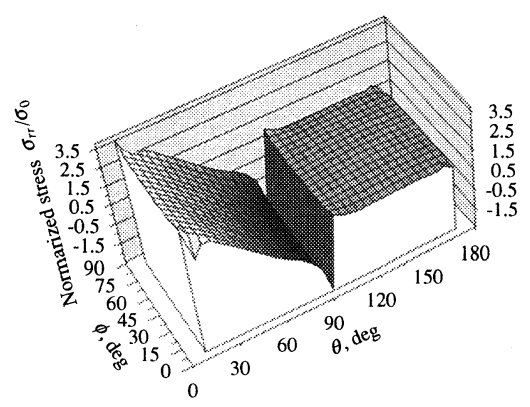

(a) Distribution of stress $\sigma_{r r}$

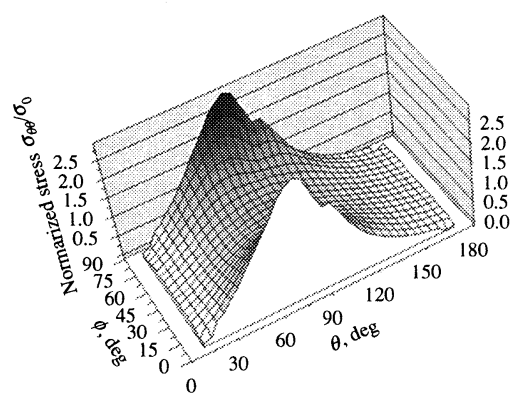

(b) Distribution of stress $\sigma_{\theta \theta}$

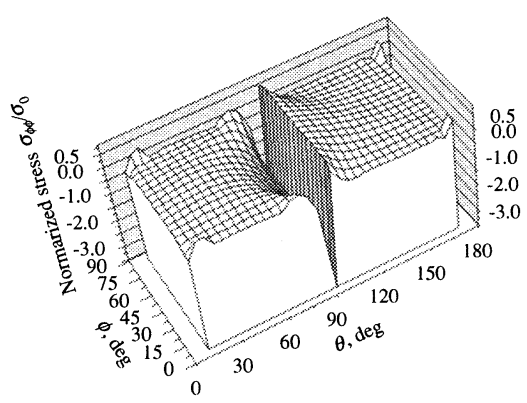

(c) Distribution of stress $\sigma_{\phi \phi}$
外の $f_{r r}, f_{r \theta}$ についても適用し，その結果を図 9,10 に 実線で示す。図 8 抢よび図 10 から界面における応力 の連続条件を完全ではないが，ほぼ満足していること がわかる。なお本研究では, 角度関数 $f_{\theta \theta}(\theta, \phi)$ は $f_{\theta \theta}^{\theta}\left(\lambda_{\text {vertex }}, \theta\right)$ と $f_{\theta \theta}^{\phi}\left(\lambda_{\text {side }}, \phi\right)$ の積であると考え, 未定 係数 $a \sim d$ を求めた.

$4 \cdot 3$ 特異応力場近傍の応力分布 次に示す応力 分布は境界要素法を用いた熱残留応力解析により得ら れた結果である。図 11 は $r / t=0.01$ におり $\theta, \phi に$ 対する $\sigma_{i j}$ の応力分布 $\left(5^{\circ} \leqq \theta \leqq 175^{\circ}, 5^{\circ} \leqq \phi \leqq 85^{\circ}\right)$ であ る. 各応力は固有值解析と同様に $\theta=90^{\circ}, \phi=45^{\circ}$ に おける $\sigma_{\theta \theta}$ の值を $\sigma_{0}$ として正規化を行ってある．熱

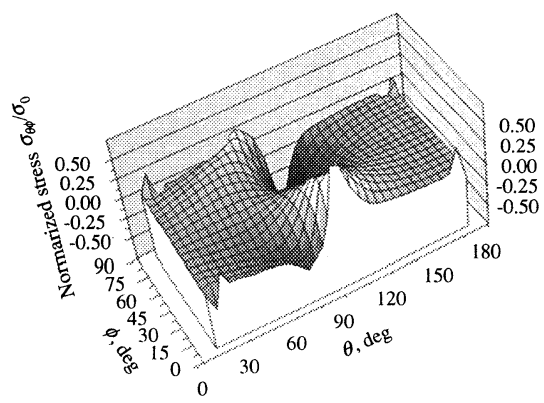

(d) Distribution of stress $\sigma_{\theta \phi}$

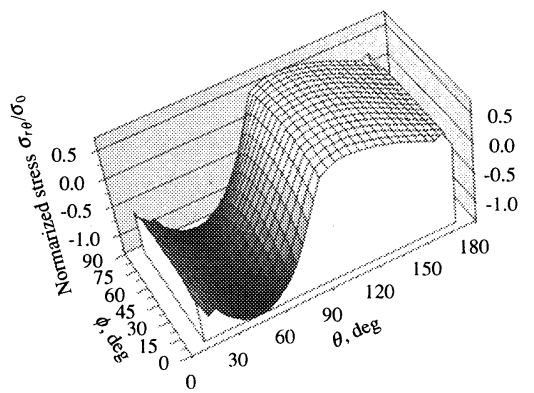

(e ) Distribution of stress $\sigma_{r \theta}$

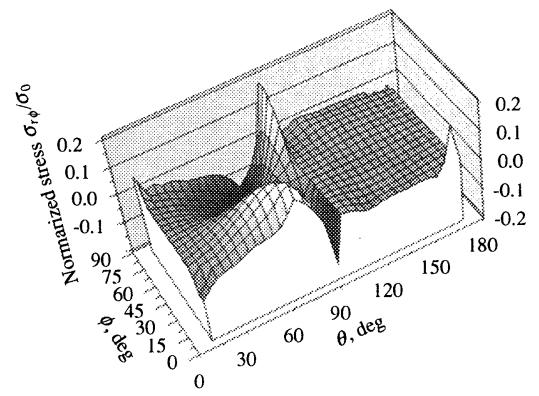

( f ) Distribution of stress $\sigma_{r \phi}$

Fig. 11 Distribution of stress components $\sigma_{i j}$ on the $\theta-\phi$ plane for $r / t=0.01$ 
残留応力の分布は図 4 に示した固有値解析により得ら れた $f_{i j}$ の結果と比較すると, 両者はよく合っている ことがわかる．このことから熱残留応力のように外力 が作用しない場合の応力場は, 固有值解析から得られ る角度依存関数で容易に表すことができるといえる.

次に, $r$ に対する応力分布について調べる. 図 12 は $\theta=90^{\circ}$ で $\phi=5^{\circ} \sim 45^{\circ}$ における応力 $\sigma_{\theta \theta}$ を $r / t$ に対 してプロットしたものである.図 12 から側面 $(\phi=$ $\left.0^{\circ}\right)$ に近づくに伴い，応力分布全体が大きくなってい ることがわかる。この分布を応力特異場の式（6)で $\ln \bar{r},(\ln \bar{r})^{2}$ まで対数特異性の項を考慮し, 近似す る. 近似により $r$ 方向の特異応力場の強さ $K_{1 \theta \theta}=$ 0.251 が得られた。ここで, 式( 7 )において示した $\phi$ 方向の角度依存関数である $f_{\theta \theta}^{\phi}\left(\lambda_{\text {side }}, \phi\right)$ について考察 する. 角度依存関数 $f_{\theta \theta}^{\phi}\left(\lambda_{\text {side }}, \phi\right)$ は, $r$ 方向の特異場 と同様に $\theta=90^{\circ}$ の界面上において自由表面に近づく に伴い発散する。角度依存関数 $f_{\theta \theta}^{\phi}\left(\lambda_{\text {side }}, \phi\right)$ に扔いて, $L_{1 \theta \theta}$ は応力特異線上の応力特異場の強さを表してい る.そこで, 特異応力場の強さを表すパラメータであ る $r$ 方向の特異応力場の強さ $K_{1 \theta \theta}$ および上述の $L_{1 \theta \theta}$

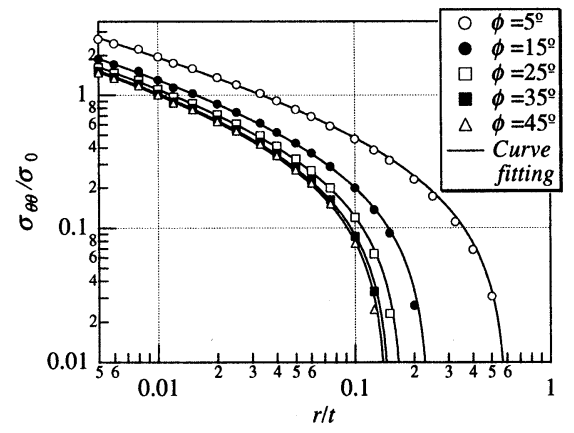

Fig. 12 Stress distribution for several $\phi$ at $\theta=90^{\circ}$ against $r / t$

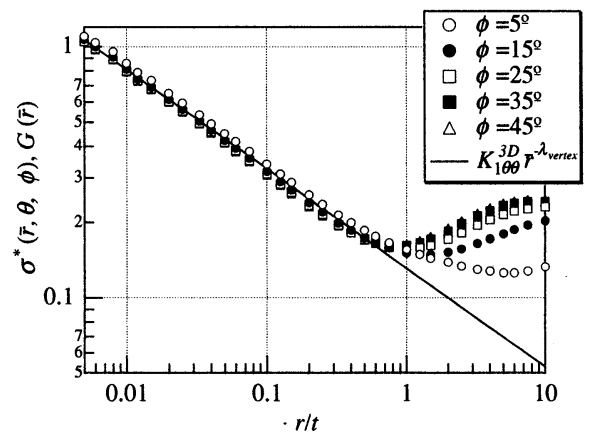

Fig. 13 Stress distribution of several $\phi$ direction at $\theta=$ $90^{\circ}$ against $r / t$
を考慮して, 三次元特異応力場における応力分布を表 すと次式のようになる。

$$
\begin{aligned}
& \sigma_{\theta \theta}\left(\bar{r}, \rho_{A}, \rho_{B}\right)=K_{1 \theta \theta}\left\{L_{1 \theta \theta}^{A} \rho_{A}^{-\lambda_{\text {side }}}+L_{1 \theta \theta}^{B} \rho_{B}^{-\lambda_{\text {side }}}\right. \\
& \quad+L_{2 \theta \theta}+\sum_{k=3}^{m} L_{k \theta \theta}^{A}\left[\ln \rho_{A}\right]^{k-2} \\
& \left.\quad+\sum_{k=3}^{m} L_{k \theta \theta}^{B}\left[\ln \rho_{B}\right]^{k-2}\right\} \bar{r}^{-\lambda \text { vertex }} f_{1 \theta \theta}^{\theta}\left(\theta, \lambda_{\text {vertex }}\right) \\
& \quad+K_{2 \theta \theta} f_{2 \theta \theta}(\theta, \phi)+\sum_{l=3}^{n} K_{l \theta \theta}[\ln \bar{r}]^{l-2} f_{(l+2) \theta \theta}(\theta, \phi)
\end{aligned}
$$

この式で対数項を考慮せず, 解析モデルの対称性 $(\phi$ $\left.=45^{\circ}\right)$ から $L_{1 i j}^{A}=L_{1 i j}^{B}$ であることを考慮すると式(12) は以下のように書ける。

$$
\begin{aligned}
& \sigma_{\theta \theta}\left(\bar{r}, \rho_{A}, \rho_{B}\right)=K_{1 \theta \theta} L_{1 \theta \theta}\left[\rho_{A}^{-\lambda_{\text {side }}}+\rho_{B}^{-\lambda_{\text {side }}}\right. \\
& \left.+\left(L_{2 \theta \theta} / L_{1 \theta \theta}\right)\right] \bar{r}^{-\lambda_{\text {vertex }}} f_{1 \theta \theta}^{\theta}\left(\theta, \lambda_{\text {vertex }}\right) \\
& +K_{2 \theta \theta} f_{2 \theta \theta}(\theta, \phi)
\end{aligned}
$$

この式の $r$ 方向の特異応力場の強さと応力特異線の 特異応力場の強さの積 $K_{1 \theta \theta} L_{1 \theta \theta}$ が, 三次元の特異応力 場の強さであると考える.ここで, 三次元の特異応力 場の強さを $K_{1 \theta \theta}^{3 D}$ とすると, 本研究の解析モデルの特

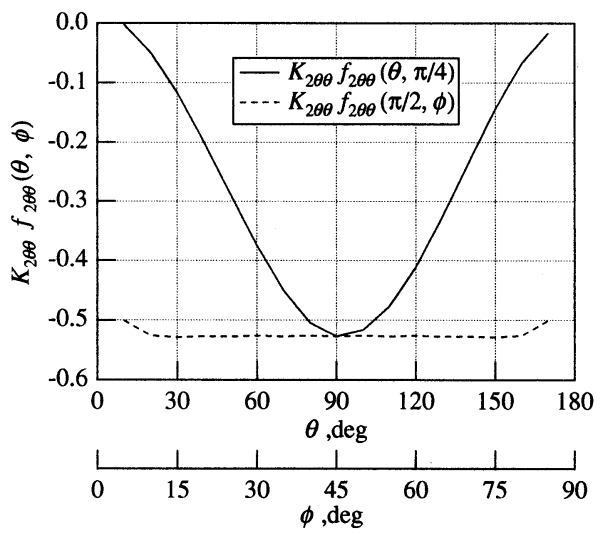

Fig. 14 Coefficients of $K_{2 \theta \theta} f_{2 \theta \theta}(\theta, \phi)$

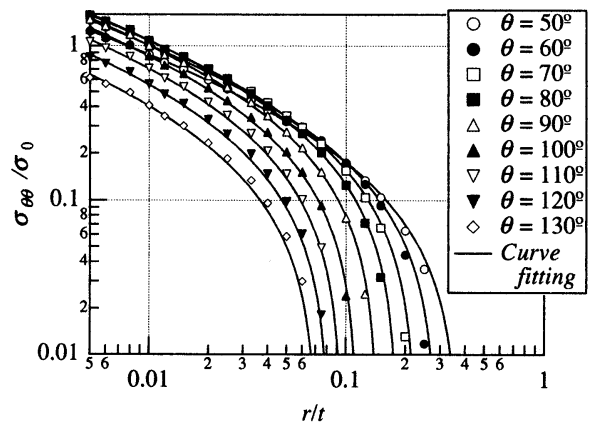

Fig. 15 Stress distribution for several $\theta$ at $\phi=45^{\circ}$ against $r / t$ 


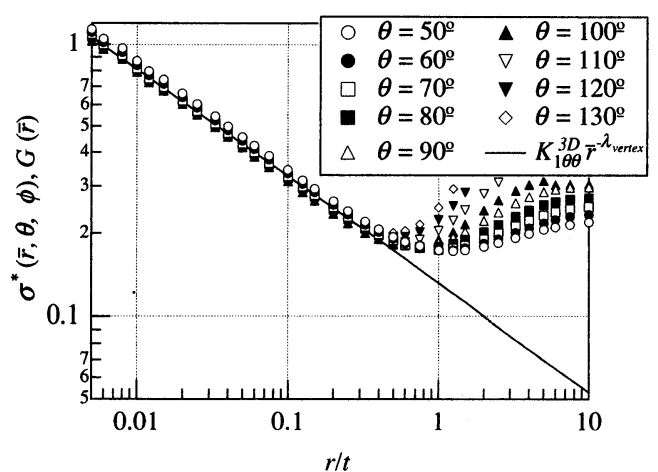

Fig. 16 Stress distribution for several $\theta$ at $\phi=45^{\circ}$ against $r / t$

異応力場の強さは $K_{1 \theta \theta}^{3 D}=0.134$ となる. 式(13)を変形 して $K_{1 \theta \theta}^{3 D} \bar{r}^{-\lambda \text { vertex }}$ を求めると, 次式が得られる.

$$
\begin{aligned}
& K_{1 \theta \theta}^{3 D} \bar{r}^{-\lambda_{\text {vertex }}}= \\
& \frac{\sigma_{\theta \theta}\left(\bar{r}, \rho_{A}, \rho_{B}\right)-K_{2 \theta \theta} f_{2 \theta \theta}(\theta, \phi)}{\left[\rho_{A}^{-\lambda_{\text {side }}}+\rho_{B}^{-\lambda_{\text {side }}}+\left(L_{2 \theta \theta} / L_{1 \theta \theta}\right)\right] f_{1 \theta \theta}^{\theta}\left(\theta, \lambda_{\text {vertex }}\right)}
\end{aligned}
$$

いま，この式の左辺を $G(\bar{r})$ とおく。この式は角度 $\phi, \theta$ によないはずである。一方, 右辺は角度 $\phi, \theta$ の影響により変化する可能性がある。いま，右辺を $\sigma^{*}(\bar{r}, \theta, \phi)$ とする. $G(\bar{r})$ および $\sigma^{*}(\bar{r}, \theta, \phi)$ を $\bar{r}$ に対してプロットした結果が図 13 である.ここで, $K_{2 \theta \theta} f_{2 \theta \theta}(\theta, \phi)$ は図 12 の応力分布を近似することによ り求めた。 $\phi, \theta$ に対する $K_{2 \theta \theta} f_{2 \theta \theta}(\theta, \phi)$ を図 14 に示 す.図 13 を見ると $r / t<0.3$ において指数特異性が支 配的であり， $\phi$ 方向の $\sigma_{\theta \theta}$ の分布の角度依存性は式 (13)により表せることがわかる.図 15 は $\phi=45^{\circ}$ に おける $\theta=50^{\circ} \sim 130^{\circ}$ の応力 $\sigma_{\theta \theta}$ を $r / t$ に対してプロ ットしたものである. 図 13 と同様に $G(\bar{r})$ および $\sigma^{*}(\bar{r}, \theta, \phi)$ の $r / t$ に対する分布を図 16 に示す. $\phi$ 方 向と同様に, $r / t<0.3$ において三次元の指数特異性が 支配的であり, $\theta$ 方向の角度依存性は $f_{\theta \theta}^{\theta}\left(\lambda_{\text {vertex }}, \theta\right)$ お よび $\rho_{A}, \rho_{B}$ で表すことができることがわかる.

以上のように三次元接合体角部の特異応力場の強さ は, 特に応力特異線上の応力特異性と関係のある応力 成分では, 三次元角部から見て $r$ 方向および $\phi$ 方向 の角度依存関数の特性を考慮しながら求めることが必 要である.この点が二次元接合体界面端における特異 応力場の強さの求め方の違いといえる.

\section{5. 結 言}

本論文は中間層を有する三次元異材接合体の熱残留 応力の特異応力場を詳細に調べたものである．その結
果をまとめると以下のようになる。

（1）固有変位ベクトルおよび境界要素法から得た 特異応力場の分布を $\theta=90^{\circ}, \phi=45^{\circ}$ で無次元化を行 い, 球面座標上にプロットした。両者を比較した結果, よく合っていることがわかった。

（2）三次元接合体角部を原点とする球座標系で界 面 $\left(\theta=90^{\circ}\right)$ と $\phi$ 方向で自由表面との交点は応力特異 線上の応力特異性を有している。このことを考慮して 応力場の角度依存関数を定義し, 三次元接合体の角部 における特異応力場を表す必要があることがわかっ た.

（3） $\phi$ 方向の特異応力場の強さと $r$ 方向の特異 応力場の強さの積により三次元の特異応力場の強さを 決定した。

（4）二次元接合体の特異応力場の式で $\phi=45^{\circ}$ に おける応力分布を，ある程度近似できることがわかっ た.

\section{文献}

(1) Miura, K., Nishimura, A., Kawai, S. and Nishi, K., Transactions of the Japan Society of Mechanical Engineers, Series A, Vol. 55, No. 516 (1989), pp. 1763-1769.

(2) Seo, K., Kusaka, M., Nogata, F., Terasaki, T., Nakao, Y. and Saida, K., Transactions of the Japan Society of Mechanical Engineers, Series A, Vol.55, No. 510 (1989), pp. 312-317.

(3) Kobayashi, H., Arai, Y., Nakamura, H. and Nakamura, M., Transactions of the Japan Society of Mechanical Engineers, Series A, Vol.55, No. 512 (1989), pp. 750-754.

(4) Bogy, D. B., On the Problem of Edge-Bonded Elastic Quarter Planes Loaded at the Boundary, International Journal of Solids and Structures, Vol.6 (1970), pp. 1287-1313.

(5) Bogy, D. B., Two Edge-Bonded Elastic Wedges of Different Materials and Wedge Angles under Surface Tractions, Journal of Applied Mechanics, Vol. 38 (1971), pp. 377-386.

(6) Bogy, D. B. and Wang, K. C., Stress Singularities at Interface Corners in Bonded Dissimilar Isotropic Elastic Materials, International Journal of Solids and Structures, Vol. 7 (1971), pp. 993-1005.

( 7 ) Dempsey, J. P. and Sinclair, G. B., On the Stress Singularities in the Plane Elasticity of the Composite Wedge, J. Elasticity, Vol. 9 (1979), pp. 373-391.

(8) Yuuki, R. and Xu, J.O., Transactions of the Japan Society of Mechanical Engineers, Series A, Vol. 58, No 556 (1992), pp. 2394-2400.

(9) Munz, D. and Yang, Y. Y., Stress Singularity at the Interface in Bonded Dissimilar Materials Under Mechanical and Thermal Loading, Journal of Applied Mechanics, Vol. 59 (1992), pp. 857-861.

(10) Munz, D., Matthias, A. and Yang, Y.Y., Thermal Stresses in Ceramic-Metal Joints with an Interlayer, Journal of the American Ceramic Society, Vol. 78, No. 2 (1995), pp. 285-290.

(11) Ioka, S., Masuda, K. and Kubo, S., Singular Stress 
Distributions near the Edge of Interface of Bonded Dissimilar Materials with an Interlayer, Journal of the Society of Materials Science, Vol. 53, No. 8 (2004), pp. 841-845.

(12) Koguchi, H., Yamaguchi, M., Minaki, K. and Prukvilailert, M., Transactions of the Japan Society of Mechanical Engineers, Series A, Vol.69, No.679 (2003), pp. 585-593.

(13) Inoue, T., Koguchi, H. and Yada, T., Transactions of the Japan Society of Mechanical Engineers, Series A, Vol. 61, No. 581 (1995), pp. 73-79.

(14) Pageau, S. S. and Bigger, Jr. S. B., Finite Element
Evaluation of Free-Edge Singular Stress Fields in Anisotropic Material, International Journal for Numerical Methods in Engineering, Vol. 38 (1995), pp. 2225-2239.

(15) Koguchi, H., Sakai, H. and Prukvilailert, M., Transactions of the Japan Society of Mechanical Engineeers, Series A, Vol. 71, No. 703 (2005), pp. 402-410.

(16) Monchai, P. and Koguchi, H., Boundary element analysis of the stress field at the singularity lines in threedimensional bonded joints under thermal loading, $J$. Mechanics of Materials and Structures, Vol.2, No.1 (2007), pp. 149-166. 